\title{
Genetics of Crouzon Syndrome
}

\author{
Aida Ariella ${ }^{1}$ Elza Ibrahim Auerkari ${ }^{2 *}$ \\ ${ }^{1}$ Pediatric Dentistry Residency Program, Faculty of Dentistry, Universitas Indonesia, Jakarta \\ 10430, Indonesia \\ ${ }^{2}$ Department of Oral Biology, Faculty of Dentistry, Universitas Indonesia, Jakarta 10430, \\ Indonesia \\ *Email: elza.ibrahim@ui.ac.id
}

\begin{abstract}
Premature fusion of cranial sutures is called craniosynostosis. The prevalence of this condition is approximately 1 in 2100 to 1 in 2500 births. In approximately $20 \%$ of cases, mutations in single genes can be identified as causative agents of craniosynostosis. The most common form of craniosynostosis is called Crouzon syndrome. The fibroblast growth factor receptor 2 (FGFR2) gene is involved in the pathogenesis of Crouzon syndrome. This gene belongs to a family of transmembrane tyrosine kinases and is located on 10q26.13. The function of FGFR2 is to regulate the process of intracellular signaling. The inheritance pattern of Crouzon syndrome is autosomal dominant, whereby a single copy of the altered gene in each cell results in an affected individual. In addition to genetic factors, epigenetics also plays a role in Crouzon syndrome.
\end{abstract}

Keywords: Crouzon syndrome, Craniosynostosis, FGFR2 gene, Intracellular signaling

\section{Introduction}

A congenital defect resulting in premature fusion of one or more sutures of the human skull is called craniosynostosis. The most frequent syndrome associated with craniosynostosis is Crouzon syndrome. Its clinical features include deformation of the skull, skeletal Class III malocclusion, maxillary hypoplasia, exorbitism, pseudoschisis and ogival palate, and a parrot-beaked nose. Affected individuals exhibit a variety of signs and symptoms, which differ in severity. People with Crouzon syndrome have normal intelligence. Craniosynostosis represents a significant medical problem, and its prevalence is estimated between 1 in 2100 and 1 in 2500 births. Possible effects of craniosynostosis are elevated intracranial pressure, airway obstruction, vision and hearing defects, damaged cerebral blood flow, difficulties in learning, and adverse psychological effects, associated with irregular skull growth $[1,2]$.

These circumstances are caused by alterations in the fibroblast growth factor receptor 2 (FGFR2) gene. FGFR2 is a part of the transmembrane tyrosine kinase family and is located on chromosome 10q26.13. Three extracellular immunoglobulinlike (Ig) domains (IgI, IgII, and IgIII), a single transmembrane segment, and a split tyrosine kinase (TK 1 and TK 2) domain together make up what we know as the 
FGFR2 gene. The FGFR2 gene is responsible for regulating processes of intracellular signaling. When the receptor binds the fibroblast growth factor, this receptor autophosphorylates, leading to activation of several intercellular proteins derived from an elevated level of tyrosine phosphorylation [3].

Crouzon syndrome is caused by an autosomal dominant mutation in the FGFR2 gene. Although other types of mutations frequently occur, missense mutations, which increase the function of the protein, account for most FGFR pathologies. Epigenetics also plays an important role in Crouzon syndrome $[2,4]$.

\section{Crouzon Syndrome}

\subsection{Definition}

Crouzon Syndrome is defined as a genetic disorder characterized by premature fusion of one or more cranial sutures of the human skull. This condition is also known as craniosysnostosis. Early fusion of the skull bones prevents the skull from growing in a normal direction and causes deformation of the head and face shape. Premature fusion of the skull bones leads to several distortions, such as wide-set, bulging eyes, a beaked nose, shallow eye sockets resulting in exopthalmos, eyes not pointing in the same direction or strabismus, hearing loss, maxilla hypoplasia, short upper lip and philtrum, and a compressed, high-arched palate. People affected by Crouzon syndrome usually have normal intelligence $[1,5]$.
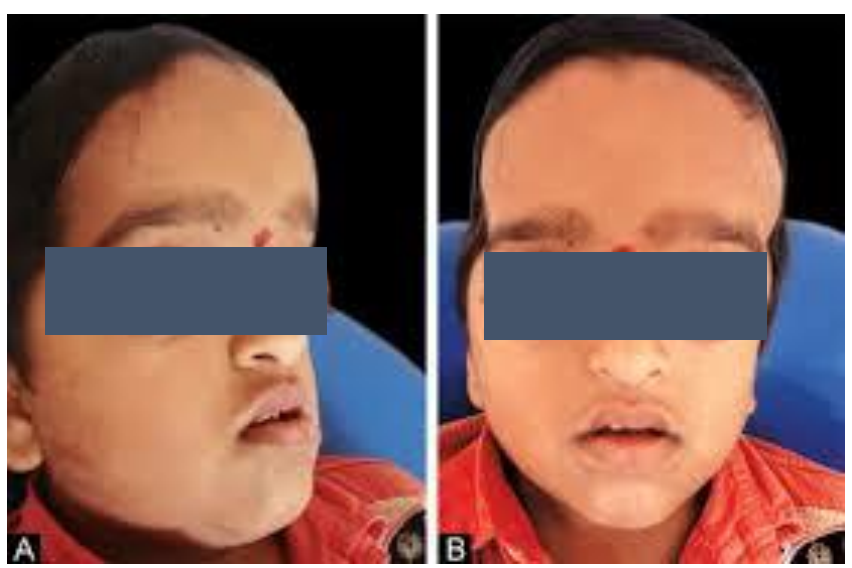

Fig 1. Clinical manifestations of Crouzon syndrome (Source : http://www.forgottendiseases.org/assets/Crouzon_Syndrome)

\subsection{Etiology}

Mutation of the FGFR2 gene is believed to be the etiology of Crouzon syndrome. FGFR2 gene mutations possibly over-trigger the process of signaling controlled by the FGFR2 protein, causing the skull bones to fuse prematurely. Crouzon Syndrome is inherited in an autosomal dominant pattern, which explains how a single copy of 
the altered gene in each cell is adequate for a person to be affected. Following the inheritance pattern, there is a $50 \%$ chance of a child being affected if either parent is affected with Crouzon syndrome [1,5].

\subsection{Prevalence}

Being the most prevalent form of craniosynostosis syndrome, Crouzon Syndrome affects approximately 16 newborns per million. The prevalence of Crouzon syndrome has been estimated at between 1 in 2100 and 1 in 2500 births [1,5].

\section{Cranial Suture Development}

During the development process, the human skull consists of nine cranial bones: two temporal bones, two frontal bones, two parietal bones, one ethmoid bone, one spheniod bone, and one occipital bone. These bones articulate with one another at fibrous tissue joints that are called cranial sutures. The human skull consists of sutures such as the sagittal suture located between two parietal bones; the coronal sutures located between the two parietal and frontal bones; the metopic suture located between the frontal bones; the lambdoid suture located between the parietal and supraoccipital bone; and the squamosal suture located between the temporal, parietal, and sphenoid bone [6].
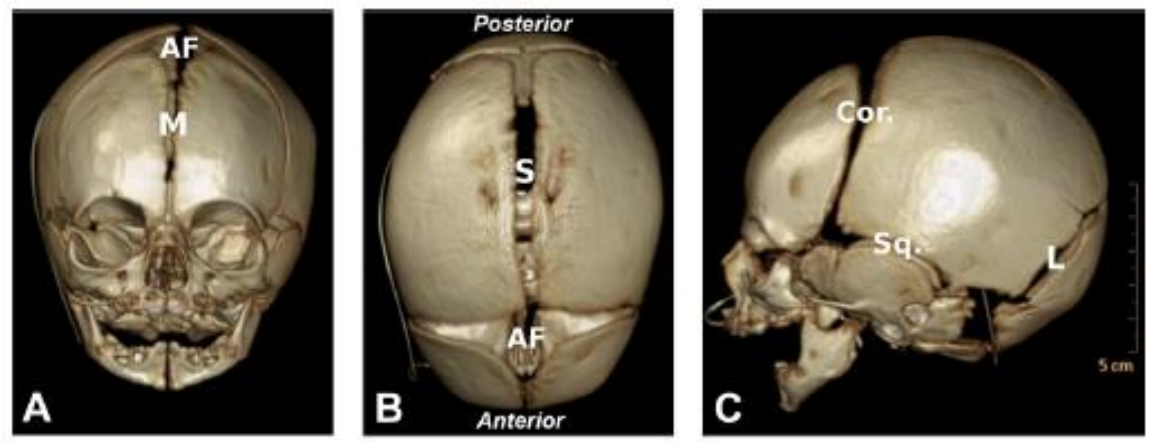

Fig 2. Three-dimensional computed tomography reconstruction of a 4-week-old patient with normal suture development. (Source: Beederman M, Farina EM, Reid RR et al. 2014) [6]

Between days 23 and 26 of gestation, the human skull begins to form, and the sutures mentioned above remain to allow for cranial vault expansion. The development of the cranial bone undergoes intramembranous ossification where the mesenchymal cells differentiate directly into osteoblasts that form bones through the secretion of osteoid matrix. The cranial suture consists of two osteogenic bone fronts, the suture's mesenchymal tissue, the dura mater underneath, and the overlying pericranium [7-9]. 


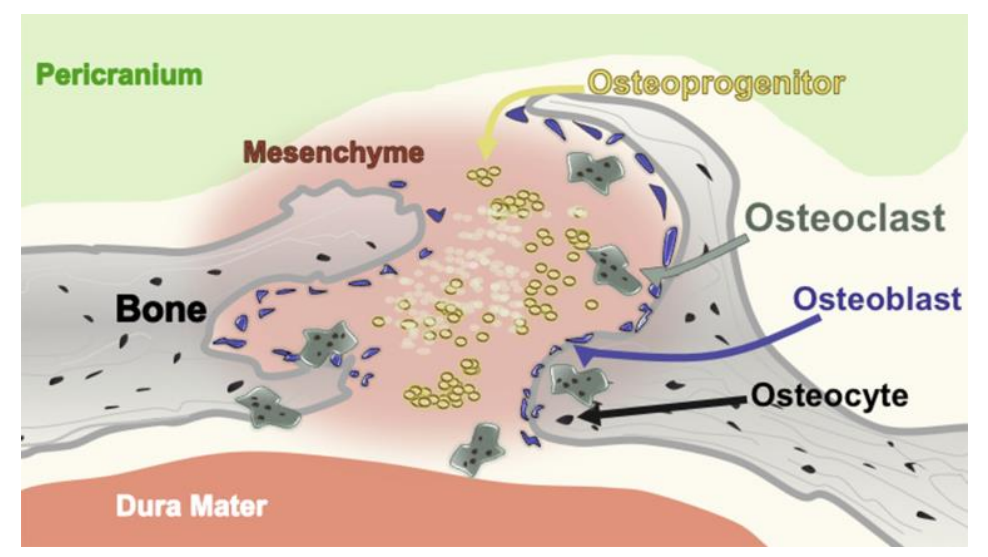

Fig 3. Schematic representation of the cranial suture complex. (Source: Beederman M, Farina EM, Reid RR et al. 2014) [6]

During cranial vault development, the cells near the two osteogenic bone fronts typically become bones through the intramembranous ossification process, while the cells in the middle of the mesenchymal tissue of the suture remain undifferentiated. Suture formation is in tight synchronicity with the development of underlying organs in order to facilitate growth. Functional impairment can occur when it is not synchronized correctly. One example of this condition is premature fusion of the cranial sutures $[6,10]$. Abnormal expansion of the skull can manifest as craniofacial asymmetries, increased intracranial pressure, mental delay, severe proptosis, strabismus, visual and airway compromise, midfacial underdevelopment, and malocclusion. Based on knowledge of the etiopathogenesis and genetic basis of the disease, it has been shown that a number of signaling pathways, cytokines, and growth factors play important roles in proper cranial vault growth and development [6].

\subsection{The Role of the FGFR2 Gene in Cranial Suture Development}

A major role in the development of cranial sutures is assigned to the FGFR2 gene from the perspective of osteoblast-related pathways. The origin of this finding is derived from the identification of altered genetic expression, molecular pathways, and environmental causes in forms of syndromic craniosynostosis. The best-established signaling pathway associated with osteoblast differentiation in suture development is the fibroblast growth factor receptor (FGFR) pathway. This molecular signaling pathway is quite complex and consists of four different receptors and over 22 ligands. During intrauterine development of the human fetus, expression of fibroblast growth factors 1,2 , and 3 has been demonstrated within the cranial sutures $[6,11,12]$.

Confirming the significant role of FGF signaling in this context, at least threepoint mutations in FGFR (for example, FGFR S252W, FGFR2, C342Y, and P253R) correlate phenotypically with syndromic craniosynostoses such as Crouzon and Apert syndromes. Such mutations alter the activation of essential receptors, ligand- 
receptor affinity, and the patterns of splicing and expression. This may in turn explain the phenotypic variability within each syndrome as well as in the mechanism of premature suture closure and disorder type [11,13].

\subsection{FGFR2 Gene Composition}

The FGFR2 gene encodes a protein called fibroblast growth factor receptor 2, one of four fibroblast growth factors. It is involved in the regulation of important processes such as cell division, cell growth and maturation, blood vessel formation, wound healing, and embryo development [14]. The ligand affinity and tissue allocation vary from one FGFR family member to another. An extracellular region which includes three immunoglobulin-like domains, a single hydrophobic membrane-spanning segment, and a cytoplasmic tyrosine kinase domain comprise a fulllength representative protein [15].

One end of the FGFR2 protein is located on the outer surface of the cell, and the other end is predominantly located inside the cell extending from the cell membrane. The position of the FGFR2 protein allows the cell to receive signals that assist the cell in responding to its environment and interacting with specific growth factors from outside the cell. Binding of growth factors to the receptor triggers a rapid succession of chemical reactions inside the cell. This process directs the cell to undergo several changes to take on specific functions, such as maturation. Several isoforms of the FGFR2 protein have been discovered in different body tissues. The tissuespecific expression pattern of FGFR2 may undergo changes throughout growth and development [14].

\subsection{Chromosomal Location of the FGFR2 Gene}

The chromosomal location of the FGFR2 gene can be shown by its cytogenic or molecular location. The cytogenic location in 10q26.13 means in the long (q) arm of chromosome 10 at position 2, band 6 , sub-band 13.14 The molecular location is base pairs $121,478,330$ to $121,598,656$ on chromosome 10 (Homo sapiens Annotation Release 108, GRCh38.p7) [14].

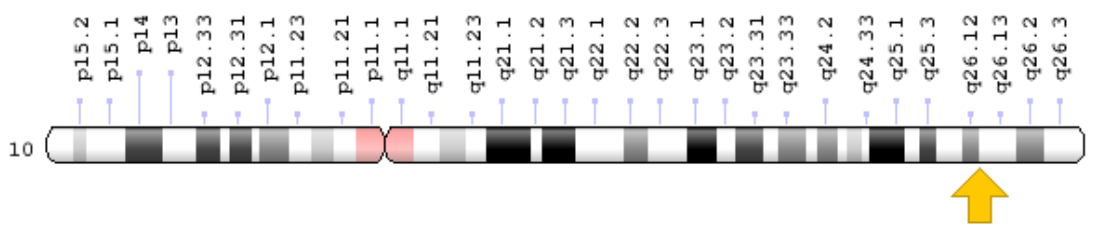

Fig 4. The cytogenic location of fibroblast growth factor receptor 2 (FGFR2). (Source: https://ghr.nIm.nih.gov/gene/FGFR2) [14]

\subsection{FGFR2 Gene Mutation}

The genotype-phenotype correlations of the human genetics most incredible series are provided by the FGFR 2 mutations. The following points are of great importance [2].

- Most of the FGFR2 mutations are missense, which means that a point mutation alters a single nucleotide to generate a codon that codes for a different amino 
acid. For example, codon GAA, which encodes the amino acid glutamic acid is changed to codon GAC, which encodes the amino acid aspartic acid. There was no explanation about nonsense or frameshift mutations [2].

- Many of the mutations are recurrent, and some missense mutations in the FGFR2 gene occur much more frequently than others. [2]

- There are many different types of phenotype outcomes of allelic missense mutations of FGFR2 [2].

- In several regions of the molecule, identical mutations are detected in FGFR paralogs [2].

- Inside one of the immunoglobulin-like domains, there are many FGFR2 missense mutations that create or even destroy a cysteine residue. This happens mainly in C342, which represents a mutational hotspot. It has been demonstrated that all but one of the amino acid substitutions result from alteration of a single nucleotide in the TGC codon [2].

- Different phenotypes may result from substitutions at the same amino acid position. For example, C342Y results in the Crouzon syndrome phenotype, whereas $\mathrm{C} 342 \mathrm{R}$ tends to give a Pfeiffer phenotype. In another example, FGFR2, S252W, and S252F cause Apert syndrome, whereas S252L usually results in a normal phenotype [2].

B

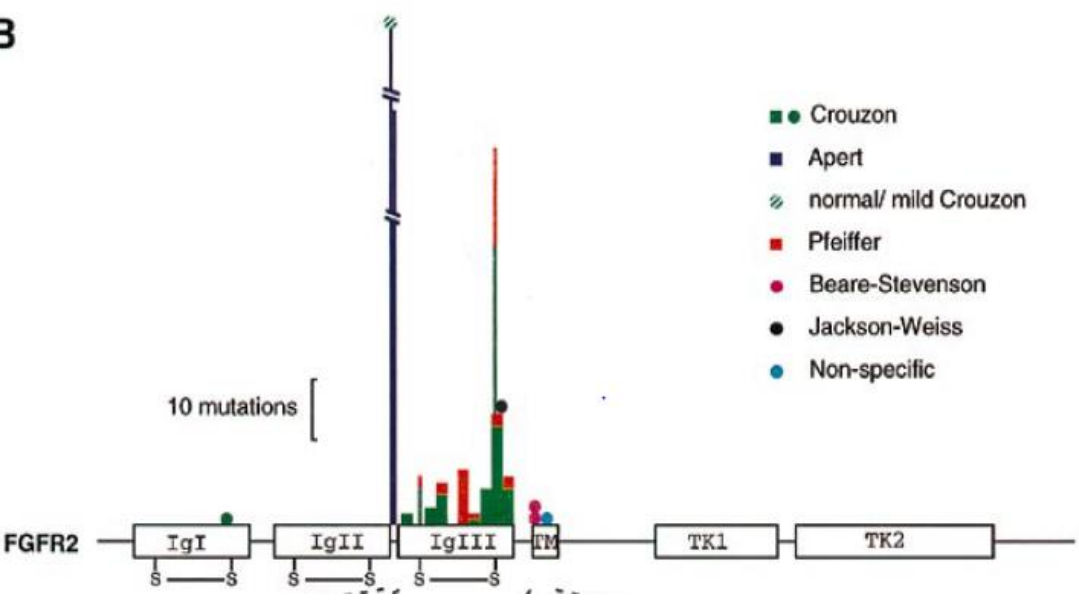

Fig 5. Histogram indicating the relative frequencies of mutations in IgII and IgIII that lead to Crouzon, Pfeiffer, and Apert syndromes. (Source: Wilkie AOM et al) [2]

In the 259 patients from the study conducted by Kan et al., there were 85 independent FGFR2 mutations. The screening strategy was carried out in the most common FGFR2 mutational hotspots, which include the first examination of the two exons, IIIa and IIIc. Kan et al. found 45 mutations of 22 different types in these two exons apart from those in the 29 Apert syndrome cases. The patients described in earlier reports conducted by Oldridge et al., Rutland et al., Przylepa et al., Glaser et al., and Johnson et al. also had this mutation. Crouzon, Pfeiffer, or Apert syndromes 
were associated with mutations in exons IIIa and IIIc, except for the $943 \mathrm{G} \square \mathrm{T}$ (A315S) and 1032G $\square \mathrm{A}$ (A344A) substitutions, which occurred in nonsyndromic coronal synostosis [4].

The pathogenic mutations of FGFR2 occur in seven different exons. They are located outside the exon IIIa or IIIc hotspot and include one mutation in IgI, another in IgII, one in the juxta-membrane region, two in tyrosine kinase I (TK 1), and four in tyrosine kinase 2 (TK 2). In a case report by Pulleyn et al., the Y105C mutation was reportedly present in a boy with Crouzon syndrome and facial asymmetry [4].

Six other mutations were discovered in the tyrosine kinase domains (TK 1 and TK 2). These mutations were first localized to the intracellular region of FGFR2. Providing solid evidence of pathogenicity, three of these mutations (K641R, K659N, and R678G0) were described to have emerged de novo. In six human subjects, the presence of the mutation E565G was concordant with the phenotype [4].

The following pathogenic FGFR2 mutations were recognized by Kan et al.

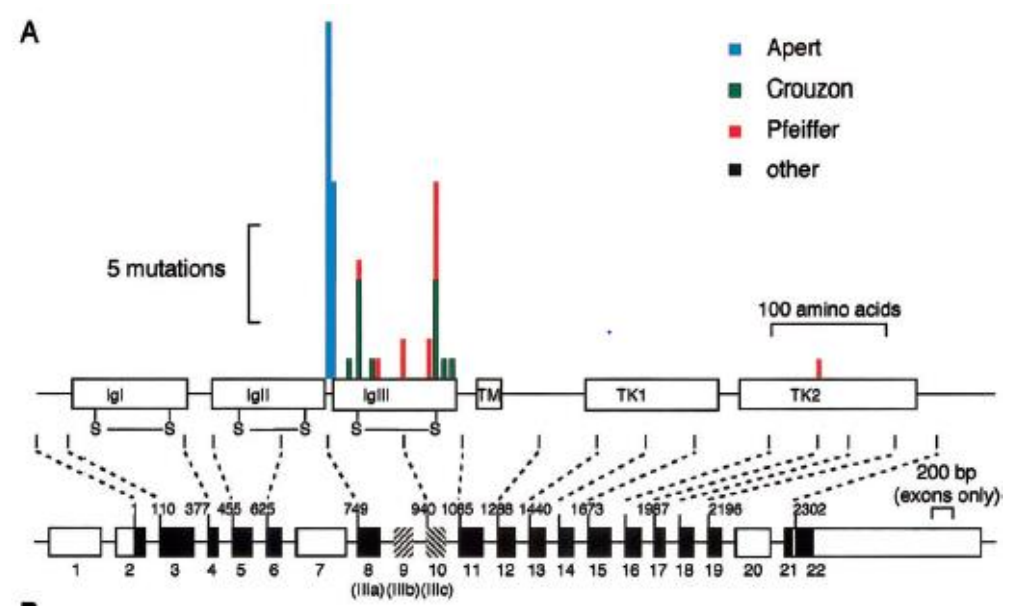

Fig 6. Shown above in a schematic of the FGFR2 domain structure is the distribution of de novo mutations of FGFR2 and a summary of their genomic organization.

(Source: Verloes A, Uspc USC, Twigg S, et al. 2017) [4] 


\begin{tabular}{|c|c|c|c|c|c|c|c|c|}
\hline \multirow[b]{3}{*}{ NUCJEOTIDE CHANGE } & \multirow{3}{*}{$\begin{array}{l}\text { AMINo Aad } \\
\text { SüsIIIUIION }\end{array}$} & \multirow[b]{3}{*}{ DOMAIN } & \multicolumn{6}{|c|}{$\begin{array}{l}\text { NO. OF UNREIATED PATIENIS WITH } \\
\text { PHENOTYPE (NO. CORROBORATED BY MOLECULAR ANALYYSIS)" }\end{array}$} \\
\hline & & & \multicolumn{2}{|c|}{ Oxford Sample } & \multicolumn{2}{|c|}{$\begin{array}{l}\text { Non-Oxford } \\
\text { Sample }\end{array}$} & \multicolumn{2}{|c|}{ Pfeiffer Sample } \\
\hline & & & Familial & De Novo & Familial & $\overline{\text { De Novo }}$ & Familial & $\overline{\text { De Novo }}$ \\
\hline \multicolumn{9}{|l|}{ Exon 3: } \\
\hline $314 \mathrm{~A} \rightarrow \mathrm{G}$ & Y105C & IgI & & & & $1 \mathrm{CS}(1)$ & & \\
\hline Exon 5: & & & & & & & & \\
\hline $514 \_515 \mathrm{GC} \rightarrow \mathrm{TT}$ & A172F & Igll & & & & & $1 \mathrm{PS}(1)$ & \\
\hline \multicolumn{9}{|l|}{ Exon 8: } \\
\hline $755 \mathrm{C} \rightarrow \mathrm{G}$ & $\$ 252 \mathrm{~W}$ & IgIII-IgIII linker & & 18 AS (11) & ..." & ..." & & \\
\hline 755 7557CGC $\rightarrow \mathrm{TCT}$ & S252L, P253S & Igll-IgIII linker & & & & $1 \mathrm{PS}(1)$ & & \\
\hline $758 \mathrm{C} \rightarrow \mathrm{G}$ & $\mathrm{P} 253 \mathrm{R}$ & Igll-IgIII linker & $1 \mathrm{AS}(1)$ & $10 \mathrm{AS}(10)$ & ..." & $\ldots$ & & \\
\hline $799 \mathrm{~T} \rightarrow \mathrm{C}$ & S267P & Igllla & & $1 \mathrm{CS}(1)$ & & & & \\
\hline $826 \mathrm{~T} \rightarrow \mathrm{G}$ & F276V & Igllla & & & & $1 \mathrm{CS}$ & & \\
\hline $833 \mathrm{G} \rightarrow \mathrm{T}$ & $\mathrm{C} 278 \mathrm{~F}$ & Igllla & & $5 \mathrm{CS}, 1 \mathrm{PS}(3)$ & & $1 \mathrm{CS}(1)$ & & \\
\hline $842 \mathrm{~A} \rightarrow \mathrm{G}$ & Y281C & Igllla & & & $1 \mathrm{CS}$ & & & \\
\hline $866 \mathrm{~A} \rightarrow \mathrm{C}$ & Q289P & Igllla & & $1 \mathrm{CS}(1)$ & & & & \\
\hline $870 \mathrm{G} \rightarrow \mathrm{T}$ & w290C & IgIIIa & & $1 \mathrm{PS}(1)$ & & $1 \mathrm{PS}(1)$ & & \\
\hline \multicolumn{9}{|l|}{ Exon 10: } \\
\hline $940-2 \mathrm{~A} \rightarrow \mathrm{T}$ & & Igllic splice acceptor & & $1 \mathrm{PS}(1)$ & & & & \\
\hline $940-2 \mathrm{~A} \rightarrow \mathrm{G}$ & & Igllile splice acceptor & & 1 PS (1) & & $1 \mathrm{PS}(1)$ & & \\
\hline $943 \mathrm{G} \rightarrow \mathrm{T}$ & A315s & Igllic & 1 Ns $(1)$ & & & & & \\
\hline $1012 \mathrm{G} \rightarrow \mathrm{C}$ & G338R & IgIIIc & $1 \mathrm{CS}$ & & & & & \\
\hline $1018 \mathrm{~T} \rightarrow \mathrm{C}$ & $\mathrm{Y} 340 \mathrm{H}$ & Igllic & & & & $1 \mathrm{CS}$ & & \\
\hline $1019 \mathrm{~A} \rightarrow \mathrm{G}$ & Y $340 \mathrm{C}$ & Iglllc & & & & $1 \mathrm{PS}$ & & \\
\hline $1021 \mathrm{~A} \rightarrow \mathrm{C}$ & T341P & Iglllic & & $2 \mathrm{PS}(1)$ & & & & \\
\hline $1024 \mathrm{~T} \rightarrow \mathrm{C}$ & $\mathrm{C} 342 \mathrm{R}$ & Igllic & & 4 PS (2) & & $1 \mathrm{PS}$ & & \\
\hline $1025 \mathrm{G} \rightarrow \mathrm{A}$ & $\mathrm{C} 342 \mathrm{Y}$ & Iglllc & $1 \mathrm{CS}$ & $4 \operatorname{CS}(4)$ & & $1 \mathrm{PS}(1)$ & & \\
\hline $1025 \mathrm{G} \rightarrow \mathrm{C}$ & C342S & Iglllc & & $1 \mathrm{PS}(1)$ & & $1 \mathrm{PS}(1)$ & & \\
\hline $1025 \mathrm{G} \rightarrow \mathrm{T}$ & $\mathrm{C} 342 \mathrm{~F}$ & Igllic & & & $1 \mathrm{CS}$ & & & \\
\hline $1026 \mathrm{C} \rightarrow \mathrm{G}$ & $\mathrm{C} 342 \mathrm{~W}$ & Iglllk & & $1 \mathrm{CS}(1)$ & & & & \\
\hline $1032 \mathrm{G} \rightarrow \mathrm{A}$ & A344A & IgllIc (cryptic splice donor) & $2 \mathrm{Cs}, 2 \mathrm{Ns}(1)$ & & & & & \\
\hline $1040 \mathrm{C} \rightarrow \mathrm{G}$ & $\mathrm{S} 347 \mathrm{C}$ & IgIIIc & & $1 \mathrm{CS}(1)$ & & $1 \mathrm{CS}$ & & \\
\hline $1061 \mathrm{C} \rightarrow \mathrm{G}$ & $\mathrm{S} 354 \mathrm{C}$ & IgIIIc & & $1 \operatorname{CS}(1)$ & & & & \\
\hline \multicolumn{9}{|l|}{ Exon 11: } \\
\hline $1124 \mathrm{~A} \rightarrow \mathrm{G}$ & Y375C & Juxta-membrane & & & & $1 \mathrm{PS}$ & & \\
\hline \multicolumn{9}{|l|}{ Exon 14: } \\
\hline $1645 \mathrm{~A} \rightarrow \mathrm{C}$ & $\mathrm{N} 549 \mathrm{H}$ & TK1 & & & & & & $2 \mathrm{CS}$ \\
\hline \multicolumn{9}{|l|}{ Exon 15: } \\
\hline $1694 \mathrm{~A} \rightarrow \mathrm{G}$ & E565G & TK1 & & & & & $1 \mathrm{PS}(1)$ & \\
\hline \multicolumn{9}{|l|}{ Exon 16: } \\
\hline $1922 \mathrm{~A} \rightarrow \mathrm{G}$ & K641R & TK2 & & & & $1 \mathrm{PS}(1)$ & $1 \mathrm{PS}(1)$ & \\
\hline $1977 \mathrm{G} \rightarrow \mathrm{T}$ & $\mathrm{K} 659 \mathrm{~N}$ & TK2 & & & & $10(1)$ & & \\
\hline \multicolumn{9}{|l|}{ Exon 17: } \\
\hline $1988 \mathrm{G} \rightarrow \mathrm{A}$ & G663E & TK2 & & $1 \mathrm{PS}$ & & & & \\
\hline $2032 \mathrm{~A} \rightarrow \mathrm{G}$ & R678G & TK2 & & & & $1 \mathrm{CS}(1)$ & & \\
\hline
\end{tabular}

Fig 7. Pathogenic FGFR2 mutations identified by Kan et al. (Source: Verloes A, Uspc USC, Twigg S, et al. 2017) [4]

Another study conducted by Kim et al. found 10 FGFR2 mutations that had been reported previously: a mutation in the IgIIIc domain (Y328C and C342Y) from four subjects and a mutation in the IgIIIa domain (C278F, W290R, and K292E) from six subjects. Direct PCR sequencing identified a new FGFR2 mutation in the TK 2 domain (L617F), replacement of leucine 617 (TTG codon) by phenylalanine (coded by TTC). According to Robertson et al., if no unpaired cysteine residues were found, the loop in the protein-binding domain would be combined. Mutation in this location resulted in a mild phenotype. The mutational analysis data from this research is as follows: [3] 


\begin{tabular}{lccc}
\hline & Gender & Mutation & Domain \\
\hline 1 & M & C278F & Ig-IIIa \\
2 & M & Q289P & Ig-IIIa \\
3 & M & W290R & Ig-IIIa \\
4 & $\mathrm{~F}$ & W290R & Ig-IIIa \\
5 & $\mathrm{~F}$ & K292E & Ig-IIIa \\
6 & $\mathrm{~F}$ & K292E & Ig-IIIa \\
7 & $\mathrm{~F}$ & Y328C & I-IIIc \\
8 & $\mathrm{~F}$ & C342Y & Ig-IIIc \\
9 & $\mathrm{M}$ & C342Y & Ig-IIIc \\
10 & $\mathrm{~F}$ & C342Y & Ig-IIIc \\
\hline 11 & $\mathrm{M}$ & L617F & IK-II \\
\hline
\end{tabular}

Fig 8. Mutation analysis data of craniosynostosis syndrome patients conducted by Kim et al. (Source: Kim M, et al. 2014) [3]

\section{Epigenetics}

Epigenetics is defined as the study of heritable changes in gene function that occur without DNA sequence alteration. This transformation may be caused by environmental factors, spontaneously, or as a result of particular mutations. Environmental factors can affect epigenetic mechanisms such as DNA methylation, histone modification (acetylation, lysine, and arginine methylation, phosphorylation, SUMOylation, ubiquitination, ADP ribosylation, proline isomerization, and deamination), and post-transcriptional silencing by interfering RNA (miRNA and microRNA). Gene activation and inactivation can be generated by any of the above-mentioned mechanisms. The outcome of the environment (for example hormonal, respiratory, and dietary factors) on the human genome can be modulated by epigenetic mechanisms through regulation of the transcriptional activity of particular genes, at particular points in time, and in particular organs. They can specify cellular variation without changing the sequence of DNA $[16,17]$.

Epigenetic modifications are important to many processes inside and outside of cells and are necessary to most organismal functions, such as senescence, X chromosome inactivation, cellular reprogramming, and imprinting. Serious injurious health effects, such as cancer or congenital diseases, may result from incorrect modifications. Early detection and prognosis of potentially new cancer biomarkers are classified as epigenetic modifications. Moreover, new therapeutic strategies and medication designs reflect the possibility of changing epigenetic modifications [17].

Further information on epigenetic mechanisms will be elaborated as follows:

- DNA methylation: without changing the primary sequence of DNA, a methyl group is added to one of the bases in the deoxyribonucleic acid chain. One of the most important mechanisms for gene silencing during the development of an embryo is DNA methylation, which is commonly repressive to transcription. Cytosine and adenine methylation are commonly studied types of DNA modification. Nowadays, the main techniques for studying DNA methylation are capture or quantification of methylated DNA, sodium bisulfite modification, and sequence-specific enzyme digestion [17]. 


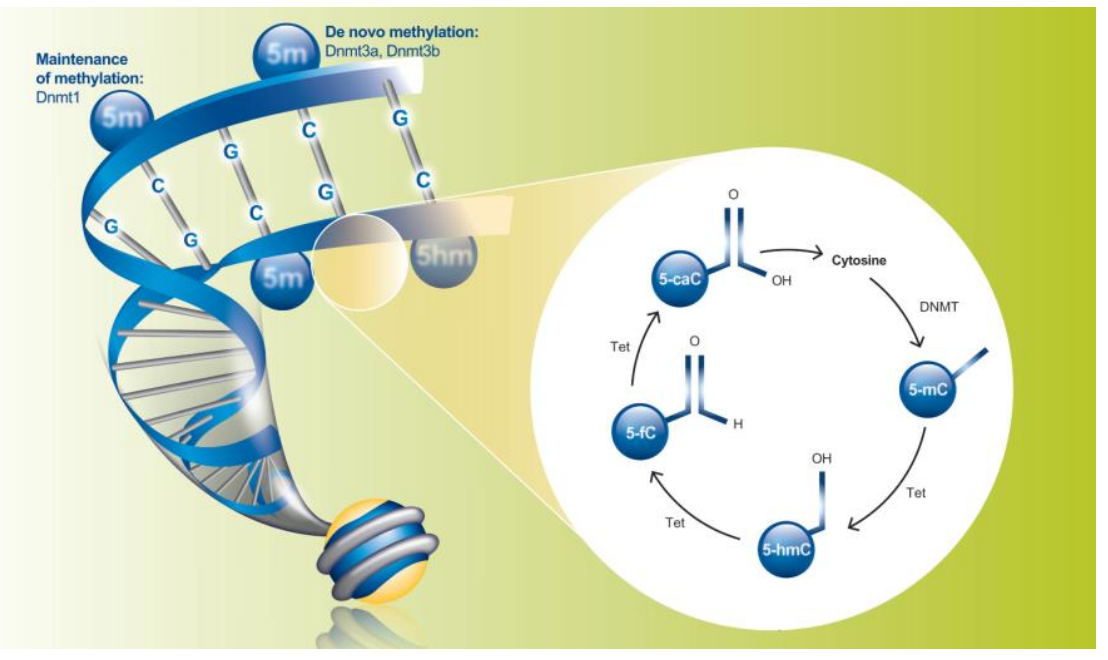

Fig 9. DNA methylation and demethylation overview. (Source: Abcam Guide to Epigenetics) [17]

- Histone modification: DNA is wrapped around histones and packaged into nucleosomes, which constitute the chromatin. Two subunits of histones H2A, $\mathrm{H} 2 \mathrm{~B}, \mathrm{H} 3$, and $\mathrm{H} 4$ are present in each nucleosome. These are known as the histones cores. H1 or the linker histone serves as a stabilizer of the internucleosomal DNA and does not establish part of the nucleosome [17].

A large number of post-translational modifications occur on histones, which divide the genome into "inactive" regions, called the heterochromatin, where DNA is denser and less attainable for transcription, and "active" regions, called the euchromatin, where DNA is attainable for transcription [17].

Catalyzed by a specific set of enzymes, nine different types of histone modifications have been presented. The best acknowledged modifications are serine/threonine/tyrosine phosphorylation, lysine and arginine methylation, serine/threonine ubiquitylation lysine acetylation. Other types of modifications include proline isomerization, krotonilation, citrullination, and GicNAcylation [17]. 


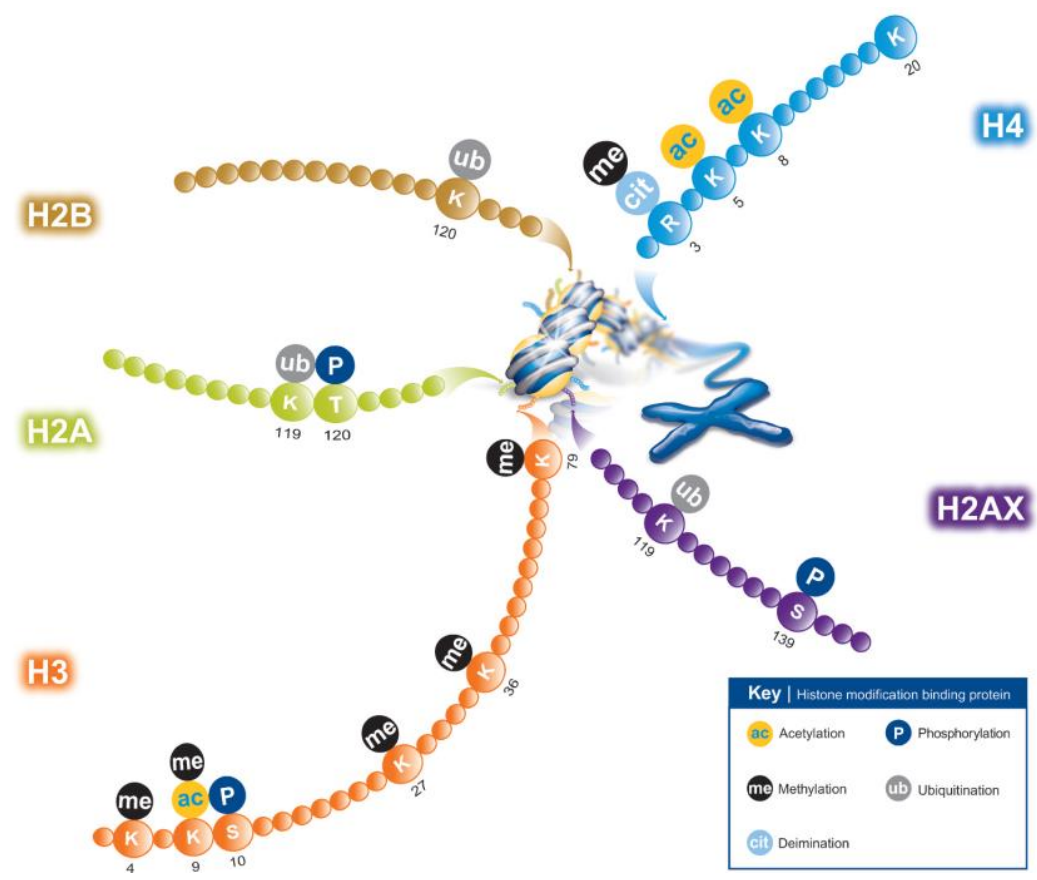

Fig 10. Schematic of the most common epigenetic histone modifications. (Source: Abcam Guide to Epigenetics) [17]

- Post-transcriptional silencing of RNA (non-coding RNAs): according to recent studies, $90 \%$ of the eukaryotic genome is transcribed. Interestingly, proteins are coded by only $1 \%-2 \%$ of these transcripts. Most of them are transcribed as noncoding RNAs (ncRNAs). During gene expression, ncRNAs play an important role in epigenetic regulation. Equally important roles are played during transcriptional and post-transcriptional events [17].

Infrastructural and regulatory ncRNAs are two types of non-coding RNAs. In the processes of transcription and splicing, infrastructural ncRNAs serve as housekeepers. These include transfer, ribosomal, and small nuclear RNAs. Regulatory ncRNAs are needed for modification of other RNAs. They are categorized into small interfering RNAs, microRNAs, promoter-associated RNAs, long, non-coding RNAs, enhancer RNAs, and piwi-interacting RNAs [17].

\subsection{Epigenetics Associated with Crouzon Syndrome}

Among individuals with identical pathogenic variants of FGFR2, a wide variety of phenotypes are displayed. Despite being in the same family, bilateral or unilateral coronal synostosis was caused by different pathogenic variants in FGFR2. In a study of 47 individuals, unilateral craniosynostosis that showed orbital hypertelorism and asymmetric brachycephaly was strongly associated with a recognized pathogenic variant in FGFR2 [18]. 
The correlation between the protein variant A391E in FGFR3 and the pathologies seen in individuals with Crouzon syndrome is one of the genotype-phenotype associations specific to this syndrome. Moreover, severe ocular problems, such as astigmatism, strabismus, amblyopia, ptosis, cleft palate, humeroradial synostosis, and nasolacrimal stenosis, are seen more frequently in individuals with the protein pathogenic variant S252W in FGFR2. In individuals with the protein pathogenic variant P253R in FGFR2, the degree of intellectual disability and syndactyly is more significant. Pathogenic variants seen in individuals with Crouzon, Jackson-Weiss, and Pfeiffer syndromes occur in and around the B exon of the third immunoglobulin-like domain in FGFR2 [18].

Identical pathogenic variants were described in individuals with Crouzon, Jackson-Weiss, and Pfeiffer syndromes, suggesting that epigenetic factors or unlinked modifier genes help to determine the final phenotype. Interestingly, the Crouzon syndrome phenotype was specifically produced by FGFR2 pathogenic variants generating residues W290G, W290R, and Y340H. On the other hand, serious forms of Pfeiffer syndrome were produced by different amino acid substitutions at the same positions (W290C and Y340C) [18].

\section{Conclusion}

The knowledge discussed in this paper increases our understanding of the etiology, prevalence, gene mechanisms, and gene mutations involved in Crouzon syndrome. Apart from the explanation mentioned above, additional research should be conducted to further elucidate the genomics of craniosynostosis, particularly Crouzon syndrome. One of the most fundamental components of management of craniosynostosis is the genetic workup, as it assists in risk assessment for the family and provides information of prognostic value to the patient. It is possible that a single molecular etiology remains to be discovered in a further $10 \%-15 \%$ of individuals, even though the molecular bases of the common craniosynostosis syndrome have been explained. Considerations should be given to other mechanisms of disease besides whole genome assessment of copy number changes and DNA sequencing to identify further predisposing factors.

\section{References}

1. Johnson D, Wilkie AO. Craniosynostosis. Eur J Hum Gen. 2011;19(4):369.

2. Wilkie AO. Craniosynostosis: genes and mechanisms. Hum Mol Gen. 1997;6(10):164756.

3. Suh YJ, Bae HS, Choi JY, Lee JH, Kim MJ, Kim S, Ryoo HM, Baek SH. A novel FGFR2 mutation in tyrosine kinase II domain, L617F, in Crouzon syndrome. J Cell Biochem. 2014;115(1):102-10.

4. Kan SH, Elanko N, Johnson D, Cornejo-Roldan L, Cook J, Reich EW, Tomkins S, Verloes A, Twigg SR, Rannan-Eliya S, McDonald-McGinn DM. Genomic screening of fibroblast growth-factor receptor 2 reveals a wide spectrum of mutations in patients with syndromic craniosynostosis. Am J Hum Gen. 2002 Feb 1;70(2):472-86.

5. US National Library of Medicine. Crouzon Syndrome [Internet]. Maryland. 2017. Available from: https://ghr.nlm.nih.gov/condition/crouzon-syndrome. Accessed date

6. Beederman M, Farina EM, Reid RR. Molecular basis of cranial suture biology and disease: osteoblastic and osteoclastic perspectives. Gen Dis. 2014;1(1):120-5. 
7. Vu HL, Panchal J, Parker EE, Levine NS, Francel P. The timing of physiologic closure of the metopic suture: a review of 159 patients using reconstructed 3D CT scans of the craniofacial region. J Craniofac Surg. 2001;12(6):527-32.

8. Cunningham ML, Heike CL. Evaluation of the infant with an abnormal skull shape. Curr Opinion Ped. 2007;19(6):645-51.

9. Slater BJ, Lenton KA, Kwan MD, Gupta DM, Wan DC, Longaker MT. Cranial sutures: a brief review. Plastic Reconstructive Surg. 2008;121(4):170e-8e.

10. Hukki J, Saarinen P, Kangasniemi M. Single suture craniosynostosis: diagnosis and imaging. In Craniofacial Sutures 2008; 12: 79-90). Karger Publishers.

11. Wilkie AO, Patey SJ, Kan SH, van den Ouweland AM, Hamel BC. FGFs, their receptors, and human limb malformations: clinical and molecular correlations. Am J Med Gen Part A. 2002 Oct 15;112(3):266-78.

12. Delezoide AL, Benoist-Lasselin C, Legeai-Mallet L, Le Merrer M, Munnich A, Vekemans M, Bonaventure J. Spatio-temporal expression of FGFR 1, 2 and 3 genes during human embryo-fetal ossification. Mechanisms Develop. 1998;77(1):19-30.

13. Ibrahimi OA, Eliseenkova AV, Plotnikov AN, Yu K, Ornitz DM, Mohammadi M. Structural basis for fibroblast growth factor receptor 2 activation in Apert syndrome. Proceedings of the National Academy of Sciences. 2001 Jun 19;98(13):7182-7.

14. US National Library of Medicine. FGFR2 gene [Internet]. Maryland. 2017. Available from: https://ghr.nlm.nih.gov/condition/crouzon-syndrome.

15. FGFR2 gene (Fibroblast Growth Factor Receptor 2) [Internet]. Genscript.com. 2018, Available from: https://www.genscript.com/FGFR2-gene.html

16. Hartsfield Jr JK, Morford LA, Otero LM. Genetic factors affecting facial growth. In Orthodontics-Basic Aspects and Clinical Considerations 2012. InTech.

17. Abcam. A guide to epigenetics. In: Chromatin. Available from: http://docs.abcam.com/pdf/chromatin/a-guide-to-epigenetics.pdf.

18. Robin NH, Falk MJ, Haldeman-Englert CR. FGFR-related craniosynostosis syndromes in Pagon RA, Adam MP, Ardinger HH, Wallace SE, Amemiya A, Bean LJH, et al.(eds): GeneReviews ${ }^{\circledR}[$ Internet]. Seattle, WA: University of Washington. 1993;2016. 